\title{
Research on the Agricultural E-Commerce in Consumer's Perspective
}

\author{
Qian Chen ${ }^{1, a}$ \\ ${ }^{1}$ Wuhan Donghu University, Wuhan, Hubei, 430212 \\ ${ }^{a}$ email
}

KEYWORDS: Agriculture Product; E-Commerce; Consumption

\begin{abstract}
Agriculture product e-commerce has developed rapidly in recent years. Based on the literature review of agriculture product e-commerce, the study answers the question that what impacts the consumer buy agriculture products online from the consumer's perspective. From the conclusion of survey of Honghu area in hubei province in China, the main factors impact agriculture online purchase include the commodity quality, the price, the logisitic and e-brand of agriculture products.in order to promote the online consumption of agriculture products, there are some measurements should be adopted, those are complete the quality standard system, setup sound logistic network, build e-brand and promote the certificate from the third party.
\end{abstract}

\section{Introduction}

With the rapid development of e-commerce, electricity supplier in the form of online shopping transactions are increasingly at the core of society, consumer demand for products is also becoming more diverse. Characteristics of agricultural products as green, in line with people's concept of green consumption, and low price, variety, shopping platform in the network more and more consumers. To December 2014, the number of sellers on the platform Ali engaged in agricultural products was 762,100 , the annual sales of 48.302 billion yuan to complete the agricultural products, and to maintain an annual growth rate of $16 \%$ or more. Agricultural development of e-commerce in a strong spending power driven, with a very broad market potential.

Foreign scholars study earlier agricultural e-commerce, China's agricultural research and exploration on e-commerce e-commerce began on agricultural research literature in 2000, the first it was just a vague concept. As the concept gradually clear agricultural electronic commerce and universal concern, agricultural e-commerce as an integral part of the agricultural e-commerce, it has gradually been widespread concern and become a hot research field of agricultural products circulation. Since 2007 the state has adopted the promotion of agricultural information file since domestic scholars theoretical research in this area is gradually increasing, combined with the contents of agricultural development of electronic commerce, there have been at different levels, different perspective of research and discussion.

\section{Analysis of the Formation of Agricultural E-Commerce from Consumer View}

For the electricity supplier of agricultural products, the market share is an important factor affecting the price of a large number of sales of agricultural products can generate economies of scale and spillover effects, thus reducing fixed costs of agricultural products, agricultural products provide 
electricity supplier price advantage. Compared to traditional agricultural retail market, the price advantage to attract a certain amount of agricultural products consumers choose to buy online.

Online shopping allows consumers to stay at home, just in front of the computer or a smart phone will be able to get online to buy the products they need, to break through the constraints of time brings traditional shopping, saving people time and space cost, giving consumers a great convenience, and can fully attract busy not want to waste time in the store shopping and people into online shoppers.

It features a wide variety of agricultural products, but have a strong geographical restrictions. E-commerce can break characteristics of agricultural produce distribution space constraints, consumers only need to open the shopping site in the search box enter want to buy, there will be an array of goods, "not buy, just think," produce electricity Suppliers can meet the needs of consumers to buy local characteristics of agricultural products.

\section{Consumer Willingness to Buy Agricultural E-Commerce-A Case Study of Honghu}

Only in Honghu area as an example, Honghu City, its special geographical environment, aquatic agricultural resources are very rich, which features aquatic vegetables and other agricultural products, varieties, high yield, good quality. Wherein lotus seeds, fresh lotus root, water chestnut and other agricultural annual production of thousands of tons. More than a dozen agro-processing enterprises and more than 300 agriculture-related businesses Taobao together form the basis of Honghu City to produce electricity development platform, annual sales of dried lotus seeds, fresh lotus root, water chestnut and lotus root, lotus root starch and other processing of Features thousands of tons of agricultural products, the creation of a billion dollars of output value, not only provides a large number of characteristics of agricultural resources for electricity suppliers consumers, but also to promote the increase of farmers' income.

According to Ali Institute data show that: in 2014, Honghu City ranks first in the whole network sales network Jingzhou, reaching 508 million yuan, accounting for 5.4\% of the total retail sales of social consumer goods Honghu City; Honghu commerce development index of 6.26, in Jingzhou City position the first two columns in the province ranked No. 24. In the same year, Honghu six main courier companies to send pieces to complete the amount and the recipient in amounts of 1.2 million and 4.14 million, compared to 2013 growth of $15 \%$ and $21 \%$, respectively. Number of employees 450 people by the end of 2013 increased to 620 by the end of 2014, an increase of 38\%. The rapid development of e-commerce industry, and enhance the ability of consumers to online shopping, we can join the intermediate stages of production and consumption - related data express logistics industry, get a glimpse.

1. Product quality: As income levels rise and consumers on product quality and enhance the sense of consumers on the quality of agricultural products and services have higher requirements. Since online shopping has economic form of virtual, so that counterfeit goods have a certain space exists, consumers are particularly concerned about product quality. According Honghu development of electronic business research reports, product quality and consumer willingness to buy in a large proportion. Characteristics of agricultural products to consumers in the value of local characteristics of agricultural products, if quality problems, consumer demand is difficult to be met will greatly affect consumer willingness to buy, so the quality of agricultural products is particularly important.

2. Price: The reason why e-commerce has developed rapidly because of its efficient cost benefits into the price advantage, agricultural e-commerce, too, relatively speaking, the price is lower than the traditional physical retail store, in the same products and services, consumers will choose the cheaper goods. H Important factors other than price, shop discounts, promotional activities also 
attract consumers shopping, such as the "double 11", "double 12" electric provider market audience half the activities to attract a large number of consumers.

3. Distribution: in the modern e-commerce sales, logistics and service providers follow the flow of commerce, the whole process is an important part, is the ultimate expression of the value of goods and services. Modern logistics including transportation, packaging, warehousing, loading and unloading, good logistics determines the net purchases of goods the arrival of the timeliness and quality of high quality for consumers, good logistics service plays an important factor in online shopping selection. For online sales Honghu regional characteristics processing of agricultural products, because of its poorly preserved perishable, fresh difficulty characteristics, so fast, and preservation of the ability distribution have higher requirements, so as to guarantee the achievement of the hands of consumers of agricultural products fresh, standards-compliant.

4. Brand Utility: In the electricity business environment, the consumer and the shop is under an information asymmetry in the case, because of the virtual nature of e-commerce, online shopping environment is a highly uncertain environment, shop the image display of goods is generally higher than the actual situation, consumers real information online shop goods a certain lack of understanding, it can not experience the quality of the goods, the online shopping process will generate skepticism, which will greatly hinder enhance consumer online shopping capabilities. Brand is a long-term business operations formed, it represents the merchant's product, service, credit is good or bad, excellent brand and reputation of products, services and reliable credit symbol, most consumers will choose to buy some of the more commodity having a well-known brand and good reputation.

In addition, the degree of user evaluation and business credit, attitude and quality of service in the consumer online shopping will play an important role will be to some extent affect consumer willingness to buy. Especially in the agricultural e-commerce, online sales of products generally primary agricultural products with local characteristics, comments, and the credibility of the seller is electricity consumers sell agricultural products important factor.

\section{Measures to Improve the Consumer's Willingness}

Construction of agricultural product quality standardization system needs to work together to build multi-party. In recent years, the state has adopted a large number of documents to encourage the development of electronic commerce of agricultural products, and encourage universal "Internet +" economy and "Taobao rural house". From the government level, the government should combine e-commerce platform to improve the quality of that system of agricultural products, to be perfect in the laws and regulations, and provide consumers with quality reference. As a direct participant in agricultural e-commerce environment, online shop businesses in order to increase market share and attract consumer interest, we must provide high-quality products and services. Businesses can create their own quality of the information system of agricultural products, the use of traceability systems, real-time upload growing, harvesting, packaging and agricultural information, to provide consumers with open, secure, and reliable agricultural products. Agricultural product quality standardization of construction, will be conducive to agricultural products quality and safety supervision, improve the quality and safety of agricultural products and promoting consumer willingness to buy.

Establish an efficient logistics system, and can shorten the time of circulation of agricultural products, reduce transportation losses thereby greatly enhancing the efficiency of the circulation of agricultural products and enhance online shopping agricultural arrival of timeliness, promote the upgrading of consumer online shopping intention. In the logistics system, the government should play a guiding role to support, facilitate business enterprise, third-party logistics companies and 
institutional cooperation mechanism to achieve the integration of capital, technology, infrastructure and other resources to jointly promote the construction of the logistics system. We should speed up the logistics and distribution system infrastructure, strengthen the cold chain of fresh preservation technology development and construction of warehouses, logistics industry to improve the level of technology and hardware, hardware and technical support for the electricity business logistics and transport of agricultural products, agricultural products in order to protect the integrity of the logistics and freshness; strengthening logistics systems management information system construction, improve the efficiency of logistics operations management, real-time access for consumers to be able to purchase agricultural products logistics information; the establishment of agricultural and material flow industry standards and norms, promote the institutionalization and standardization of the logistics industry and the establishment of damage responsibility system, strengthen after-sales service, improve logistics service quality agricultural products.

At this stage, there is a small agricultural business enterprise scale and number of the dispersed state, and the lack of large enterprises, agricultural business enterprise brand building lags behind. Based on this, agricultural e-commerce businesses have bigger, stronger, made the brand awareness, to be followed by the national agricultural policies and the development trend of e-commerce businesses to develop a reasonable network management strategy and management concepts, to new and diverse products and improve services for consumer services, so as to enhance brand recognition. Agricultural marketing network operators have to provide quality products and service, to maintain good business credit, enhance their brand. Agricultural products as a primary raw material of the product itself has a strong moldability, such as lotus Honghu fresh lotus root in addition to sales, but also can be made into lotus root, lotus root starch, lotus root folder, and other diverse forms and varieties of processed products, agricultural products processing enterprises as a positive forms and types of innovative products, deep processing of agricultural products mining value chain to maximize the value of agricultural development, provide a variety of products to provide consumers with a variety of options.

Consumers shop online, they often need to disclose their personal data related to financial payments and, for consumers, online shopping has certain risks. Improve the online shopping credit system is to improve the traditional consumer shopping concept, an important way to enhance the consumer online shopping intention. From the consumers' interests, development of agricultural e-commerce trading platform, you need to establish a government-led system and credit evaluation system, improve the regulatory mechanism of credit, the establishment of credit information service platform, to protect farm shop offers quality products and protect consumers online payment security. Third-party certification of agricultural products and strengthen the electricity business trading platform, to provide consumers with practical, reliable and secure service platform to improve consumers' willingness to buy online farm.

\section{Acknowledgements}

Project: This work was supported by the grants from "The Research of Agricultural information

service system construction to promote agricultural industrialization management" of Wuhan Donghu University Agriculture EC Hubei Provincial Collaborative Innovation Center.

\section{Reference:}

[1] G.Baourakis and M.Kourgiantakis.The impact of e-commerce on agro-food marketing.British Food Journal.2002,8: 580-589. 
[2] Franck.Galtier.Agricultural market information systems in developing countries: New models, new impacts.General Review.2014,23: 232-244.

[3] Ruiz Garcial, Steinberger G, Rothmund M.A model and prototype implementation for Tracking and tracing agricultural batch products along the food chain [J]. .Food Control, 2010,21: 112 121 a.

[4] Dabbene F, Gay P, Sacco N.Optimization of fresh-food supply chains in uncertain environments.Biosystems Engineering.2008,99: 348-359.

[5] Gao Hongmei Hubei Agriculture e-commerce model study [D]: Huazhong University of Science and master's degree thesis, 2013.

[6] Tianying Wei Realistic Dilemma and Path agricultural development of electronic commerce to select [J]. price Monthly, 2012 (422): 54-57.

[7] Li Jun Waves and innovation strategies in the agricultural development of electronic commerce [J]. Commercial Times, 2014 (34): 89-90.

[8]Wang Yan agricultural E-commerce Development Countermeasures Research [J]. Neijiang Normal University, 2010 (11): 47-49.

[9] Fu waves. China's agricultural e-commerce research [D]. Hunan Agricultural University master's thesis, 2010.

[10] Zhang Shengjun, road sign, Deng Xiang evaluation of e-commerce platform for the construction of agricultural and recommendations [J]. Rural Economy, 2010 (10): 103-106.

[11] Geyan Jiang, Wang to sign, Huangyan Ru agricultural e-commerce platform for building [J]. Anhui Agricultural Sciences, 2012 (11): 6916-6917.

[12] Zeng Ming Construction and Application of the county agricultural commerce platform [J]. Business Review, 2014 (21): 1-3.

[13] Like Gang Zheng Jingying e-commerce environment Agricultural Product Logistics Distribution Center [J]. Logistics Engineering and Management, 2015 (8): 51-53.

[14] Liu, Zhong "Internet +" era of new trends in the evolution of the agricultural supply chain based on the "cloud" a new model of agricultural supply chain [J]. Chinese Circulation Economics and Management, 2015 (9): 91-99.

[15] GRIDS Logistics Development Strategy of Agricultural Products achieve sales of close and docking mode [J]. Agriculture Network and Information Technology, 2015 (8): 34-38.

[16] Countermeasure Wang Shuang into the development of electronic commerce to promote agricultural products [J]. of Agricultural Sciences, 2012 (10): 387-389.

[17] Liangxue Jing current development of e-commerce and the problems and recommendations [J]. Academic Forum, 2014 (12): 77-79.

[18] The development of e-commerce and foreign agricultural Enlightenment $\mathrm{Hu}$ Yongjun, Gao Qing Peng on China [J]. Economic Research, 2015 (28): 6-10.

[19] High Ya-juan agricultural e-commerce development strategy of our country [J]. Commercial Times, 2011 (11): 35-36.

[20] Yang Yuehui agricultural e-commerce research literature review [J]. Anhui Agricultural Sciences, 2011 (18): 15-16.

[21] White Paper on E-commerce of agricultural products in 2014 Ali Ali Institute of .2014.

[22] Report on the Development of Honghu City, E-Commerce [R] Honghu City Aquatic Business Network .http: //www.hhshangwu.gov.cn. 